Author: Leslie T. Holmes

Affiliation: School of Social and Political Sciences - University of Melbourne

Degree: PhD

E-mail: leslieth@unimelb.edu.au 


\section{Book Review: Corruption}

\section{Fletcher, Clare and Herrmann, Daniela. The Internationalisation of Corruption: Scale, Impact and Countermeasures. Farnham, Gower 2012. xviii + 283.}

Their own extensive and impressive bibliography undermines the claim Clare Fletcher and Daniela Herrmann make (p.2) that 'literature on corruption is relatively sparse'. But what has been lacking - surprisingly, given the explosion of courses on corruption in the Anglophone world - is a reliable authored (as distinct from edited) introduction to corruption studies suitable for advanced undergraduates, postgraduates, and practitioners. This book could well be the one to fill that gap. While specialists on corruption will be familiar with most of the material in this book, newcomers will appreciate the facts that it is clearly written, well-structured, comprehensive and up-to-date.

Fletcher and Herrmann are both Senior Researchers at NHS Protect (a body tasked with countering corruption in the British health service) and teach on the University of Portsmouth's Masters degree in Counter Fraud and Counter Corruption Studies. It appears that this teaching has helped them determine what is needed for a textbook, and they have learnt the lesson well. Following the introductory chapter, Part One focuses on the Scope and Impact of Corruption, with chapters on 'Scale and Measurement' and 'Causes and Consequences'. Part Two comprises two chapters on combating corruption - one on the role of the state and International Organisations, the other on NGOs (primarily transnational ones). Arguably the most interesting part of the book is Part Three, which provides sector analyses and well-chosen, pithy case studies. The first chapter in the third part focuses on corruption at the elite level in world politics, and analyses the vote-buying scandal in the International Whaling Commission that emerged in 2001 as a case study. This is followed by a chapter on corruption in international business that takes the Al Yamamah/BAE scandal that first surfaced in 2004 as a prime example, and then a chapter on corruption in global finance, with a focus on Bernard Madoff's Ponzi Scheme in the USA. Three more chapters deal with, respectively, corruption and transnational organised crime (with the General Pinochet and US bank Riggs scandal as the case study); corruption in international aid (with a focus on the World Bank's Public Expenditure Tracking Survey in Uganda); and corruption in world health systems (with the problem of fake anti-malaria drugs as the case study). The very brief final - twelfth - chapter summarises the key points of the book and suggests themes in corruption studies that deserve much more research, including environmental politics and food security. 
Whilst each of the chapters in Part Three includes one in-depth case study, they all also cite numerous other examples of the various types of corruption, most of them recent; the book is rich in relevant detail. Not only does it cover just about all the topics a university course is likely to address, but this book also provides intelligent study questions at the end of each chapter, as well as plenty of useful website addresses, that make it an excellent textbook.

In a book as wide-ranging as this one, there are bound to be minor slips and contentious claims. For instance, Malaysia established a dedicated anti-corruption academy several years before the establishment of the new Vienna-based International Anti-Corruption Agency, so that the latter is not really the first of its kind (p.2) - though the Viennese academy is more genuinely international than its Malaysian counterpart. Most would agree that the international collaborative approach to combating corruption is somewhat older than the 'past ten years' (p.55) claimed by the authors. Given the emphasis the World Bank has placed on this since 2000, it would have been useful to have some explicit discussion of 'state capture' in ch.6. And the UN Protocol to Prevent, Suppress and Punish Trafficking in Persons is not the Palermo Protocol (p.167), but one of them (there are either two or three, depending on how the protocol on illicit trafficking in arms is classified).

But these are all petty quibbles. Overall, this book is an extremely valuable addition to the field. It is a pity that it is currently available only as an expensive hardback. I cannot think of another book on corruption that is so well suited to introductory university teaching, and it is to be hoped that a moderately-priced paperback edition will soon become available. 


\section{University Library}

\section{- M M I N E R VA A gateway to Melbourne's research publications}

Minerva Access is the Institutional Repository of The University of Melbourne

Author/s:

Holmes, LT

Title:

The internationalisation of corruption: scale, impact and countermeasures

Date:

2013-02-01

Citation:

Holmes, L. T. (2013). The internationalisation of corruption: scale, impact and countermeasures. CRIME LAW AND SOCIAL CHANGE, 59 (1), pp.137-138. https:// doi.org/10.1007/s10611-012-9403-0.

Persistent Link:

http://hdl.handle.net/11343/282619 